\title{
EQUIVALENCE SCALES, HORIZONTAL EQUITY AND OPTIMAL TAXATION UNDER UTILITARIANISM
}

\author{
Yves BALCER \\ University of Wisconsin-Madison, Madison, WI 53706, U.S.A., and the World Bank \\ Efraim SADKA \\ Tel-Aviv University, Tel-Aviv, Israel, and Liniversily of Michigan
}

Received December 1984, revised version received August 1985

\begin{abstract}
This paper analyzes the question of how differences in family size should be treated by the income tax system in order to achieve horizontal equity. Family size is incorporated into the demand system by the procedure of demographic scaling. Horizontal equity is defined as 'equal treatment of equals'. It is shown that when lump-sum taxes are not available and the government has to rely on income taxation, then the only way to entail equal utilities for households of different size is to equate the labor supplies and the per-standard-adult consumptions of these households.
\end{abstract}

\section{Introduction}

In this paper we analyze the question of how differences in family size should be treated by the income tax system in order to achieve horizontal equity. The answer to this question depends on (a) how differences in family size manifest themselves in the consumption patterns and labor supply (or, more generally, the preferences) of households of various sizes; and (b) how we define horizontal equity.

One of the most common procedures of incorporating demographic variables in general and household size in particular into demand systems is that called 'demographic scaling' [see Pollak and Wales $(1978,1980,1981)$ and references therein]. This method employs the idea of 'equivalence scales' or 'standard adults' in explaining the differences in demand patterns caused by household size differences. For our purposes we can describe the procedure of scaling as follows. Suppose for the sake of simplicity that there are only two family sizes: one-member and two-member families. It is assumed that a family of $i$ members $(i=1,2)$ contains $c_{i}$ 'standard adults'.

*The research reported here was financially supported by NSF Grant DAR-7917376 and by funds granted to the Foerder Institute for Economic Research by Bank Leumi Le-Israel. Comments by two anonymous referees are gratefully acknowledged. The opinions expressed are those of the authors. 
With no loss of generality, let $c_{1}=1$ (so that a family of one person has one standard adult) and write $c$ for $c_{2}$. Suppose that each family has one wageearner and consumes an aggregate consumption good $(x)$ and provides labor services $(y)$. Scaling amounts to assuming that the two-member family's preferences over bundles $(x, y)$ are the same as the one-member family's preferences over $(x / c, y)$. The rationale for this assumption is that when a family of two members has a consumption of $x$, then its per-standard-adult consumption is only $x / c$. Thus, the utility that a two-member family with $c$ standard adults derives from the bundle $(x, y)$ is the same as the utility derived by a family with only one standard adult from the bundle $(x / c, y){ }^{1}$

Turning to the question of horizontal equity there is some ambiguity in the literature about the meaning of this concept. There are in fact two principles, most often referred to as the principle of horizontal equity. Feldstein $(1976$, p. 87$)$ states that the principle of horizontal equity in tax design implies that individuals who would be equally well off in the absence of the tax should be equally well off with the tax. The tax system should preserve the utility order of individuals.' This definition of horizontal equity raises two problems. First, as Atkinson (1980, p. 16) puts it: '... it may be held to attach undue status to the pre-tax distribution'. There does not seem to be any compelling normative justification for emphasizing the preservation of the pre-tax ordinal ranking of individuals. Second, it should be quite obvious that horizontal equity, as defined above, does not follow from welfare maximization. Most social welfare functions, 'based on end-result principles, such as utilitarian or Rawlsian theories, see the distribution of post-tax income as the sole matter for concern' [Atkinson (1980, p. 18)]. Therefore a maximization of a social welfare function does not usually lead to horizontal equity. For instance, if the social welfare function is symmetric in individual utilities (e.g. the utilitarian social welfare function), then complete reversal of individual ranking has no welfare consequences: social welfare does not change if Jones, the poor, and Smith, the rich, trade positions. Namely, it does not matter whether the pre-tax rich is also the post-tax rich and the pre-tax poor is also the post-tax poor or the pre-tax rich becomes the post-tax poor and the pre-tax poor becomes the post-tax rich.

\footnotetext{
${ }^{1}$ Some may argue that, although scaling is a good way of explaining consumption patterns across families with different sizes, one should not use scaling for welfare comparisons among such families [see, for instance, Pollak and Wales (1979)]. In other words, one should not attempt to say, as we did, that a two-person family derives the same utility from $(x, y)$ as a oneperson family derives from $(x / c, y)$, for such a statement ignores the 'utility from children'. Therefore it is concluded that no special attention should be paid by tax laws to family size. Although the argument that parents derive utility from their children is not without merit, we think that such an argument should be embodied in a model with endogenous fertility [e.g. Nerlove et al. (1984)]. In our context of exogenous fertility, we do not think that the size of the family should be ignored by tax laws. We do not think that children can be simply treated as a consunntion by their parents. Children are, after all, human beings [see Nerluve et al. (forthcoming)].
} 
Another commonly held perception of horizontal equity is 'equal treatment of equals'. The question naturally arises what we mean by the loose statement 'equal treatment of equals'. According to Feldstein (1976, p. 83): 'If two individuals would be equally well off... in the absence of taxation, they should also be equally well off if there is a tax.' Note that this interpretation of the principle of horizontal equity is not identical to the principle of preservation of the pre-tax ordinal ranking of individuals [see Berliant and Strauss (1985)]. For instance, if all pre-tax poor become post-tax rich and all pre-tax rich become post-tax poor, we have rank reversals but no violation of the 'equal treatment of equals' principle, as defined above. ${ }^{2}$

However, it seems to us more natural to adopt the view of Atkinson and Stiglitz's perception of the notion of 'equal treatment of equals'. They maintain that 'the principle of horizontal equity states that those who are, in all relevant senses identical, should be treated identically' (1980, p. 353). Indeed, this is the definition of horizontal equity that we adopt in this paper. We first note that this principle of horizontal equity does not follow from a maximization of a utilitarian social welfare function [see Atkinson and Stiglitz (1976,1980), Stiglitz (1982) and Balcer and Sadka $(1979,1982)]$. Atkinson (1980, p. 14) advocates the view that horizontal equity is an independent principle that has to be balanced with maximization of welfare'. In this paper we superimpose the principle of horizontal equity on the utilitarian social welfare function, i.e. we maximize the latter function subject to the constraint that horizontal equity holds.

Second, we have to clarify what we mean by those who are in all relevant senses identical' in our definition of horizontal equity. For our purposes, it will suffice to say that we believe that family size is not a relevant sense. Third, we have to explain also what we mean by 'treated equally'. By this we do not mean to say that those who are equal should pay the same tax but rather that they should enjoy the same utility. Thus, we interpret the principle of horizontal equity to imply that families of different size should nevertheless attain the same level of utility. We believe that this notion of horizontal equity is what the designers of tax systems everywhere in the Western world have in mind, for otherwise how can we explain the tax relief that large families enjoy everywhere. This relief is usually aimed at equating the utility of the large family with that of the small family.

Thus, our aim here is not simply to maximize the utilitarian social welfare function $u\left(x_{1}, y_{1}\right)+u\left(x_{2} / c, y_{2}\right)$, where the subscripts 1 and 2 refer to onemember and two-member families, respectively, but rather to maximize it subject to the horizontal equity constraint that $u\left(x_{1}, y_{1}\right)=u\left(x_{2} / c, y_{2}\right)$. It should be fairly obvious that the latter constraint is binding because the two

\footnotetext{
${ }^{2}$ In fact, exactly this kind of rank reversal occurs under utilitarianism in some models of firstbest taxation [see Sadka (1976b)].
} 
families do not have the same marginal utility of consumption schedule: the marginal utility of the large family is only $1 / c$ of the marginal utility of the small family. Thus, a mere maximization of the utilitarian objective function will not usually lead to an equalization of utilities.

Given our formulation of the difference in the utility functions of families of different sizes, the obvious way to ensure equal utilities for such families is to equate their labor supplies and per-standard-adult consumptions, namely:

$$
y_{1}=y_{2} \text { and } \quad x_{1}=x_{2} / c
$$

However, this is certainly not the only way to guarantee horizontal equity. In fact, if the government can employ lump-sum taxes and transfers, then it never pays to equate the labor supplies and per-standard-adult consumptions of families of different size. As might be expected, the larger household should provide a lower supply of labor and have a lower level of consumption per standard adult. This is shown in section 2 .

However, one of the main results of this paper is that if lump-sum taxes and transfers are excluded and the government has to rely on income taxation, then equating the labor supplies and the per-standard-adult consumptions is the only way to entail equal utilities for households of different size (section 3). Thus, no matter what the social welfare function is, there is only one way to achieve horizontal equity: all families with the same earning ability must provide the same supply of labor and have the same perstandard-adult consumption, regardless of the size of the family. This rather strong result suggests that relying on income taxation in order to achieve horizontal equity causes some additional deadweight loss on top of the standard one which stems from the fact that an income tax creates a wedge between the marginal rate of substitution of consumption for leisure and the marginal product of labor. Section 5 illustrates the magnitude of this additional loss.

Optimal taxation theory says that when all families are of the same size, then the marginal tax rate should be non-negative everywhere and equal to zero at the bottom and top ends of the income distribution [see, for instance, Mirrlees $(1971,1976)]$. Section 4 discusses the properties of the optimal tax schedules facing the two types (by size) of households in our model economy. We show that an appropriately weighted average of these two schedules must have a marginal rate which is non-negative everywhere and equal to zero at both ends of the income distribution. But each individual schedule need not have this property. Furthermore, one of these two taxes will definitely have a marginal rate which is negative at sufficiently low and sufficiently high income levels; in fact, one of the two tax schedules may well have a marginal rate which is negative everywhere.

As we have already mentioned, the principle of horizontal equity is 
imposed throughout this paper on the utilitarian sum-of-utilities objective function for utilitarianism by itself cannot guarantee such equity. In appendix A we investigate the question whether a weighted sum of utilities, where higher weights are assigned to the larger families, can bring about horizontal equity.

\section{Horizontal equity with lump-sum taxes}

Let $u$ and $U$ be the utility functions of a one-member family and a twomember family, respectively. As explained in the introduction, it is assumed that these two utility functions are related to each other by

$$
U(x, y)=u(x / c, y) .
$$

Recall that horizontal equity is understood in this paper to mean that families with the same earning ability should enjoy the same level of utility, irrespective of their size. The earning ability or the skill of a household is identified with the wage rate of the single wage-earner in the household. Since lump-sum taxes and transfers are admissible in this section, it will suffice to consider only one wage level. Thus, we suppose that there is one one-member family and one two-member family, both facing the same wage rate, denoted by $n$.

The objective is to maximize a utilitarian social welfare function

$$
W=u\left(x_{1}, y_{1}\right)+u\left(x_{2} / c, y_{2}\right),
$$

where $x_{i}$ and $y_{i}$ are the consumption and labor supply, respectively, of the family of $i$ members, $i=1,2$. On this objective function we impose the horizontal equity principle:

$$
u\left(x_{1}, y_{1}\right)=u\left(x_{2} / c, y_{2}\right) .
$$

The first-best optimum is then obtained by maximizing the utilitarian social welfare function (2), subject to the horizontal equity principle (3), and the resource constraint

$$
x_{1}+x_{2}+R \leqq n y_{1}+n y_{2},
$$

where $R$ is some predetermined level of public consumption.

The Pareto-efficiency condition implied by our utilitarian objective requires us to equate each family's marginal rate of substitution of consumption for leisure to its wage rate. Since our two households face the same wage rate, 
then the marginal rates of substitution must be equated to each other:

$$
\frac{u_{y}\left(x_{1}, y_{1}\right)}{u_{x}\left(x_{1}, y_{1}\right)}=\frac{c u_{y}\left(x_{2} / c, y_{2}\right)}{u_{x}\left(x_{2} / c, y_{2}\right)}=-n \text {. }
$$

Since $c>1$ (it is generally believed that $1<c<2$ ), then condition (5) rules out the possibility of achieving horizontal equity [condition (3)] by equating labor supplies and per-standard-adult consumptions. In fact, assuming, as we do, that $u$ is strictly concave, then (3) and (5) imply that the larger family should work and consume per standard adult less than the smaller family (see fig. 1). The economic explanation for this result is quite straightforward: since a dollar of consumption at the disposal of the larger family means only $1 / c$ dollars per standard adult, then the smaller household is more efficient in consuming $x$. Thus, the smaller family should consume more $x$ per standard adult and, in order to maintain horizontal equity, should also work harder.

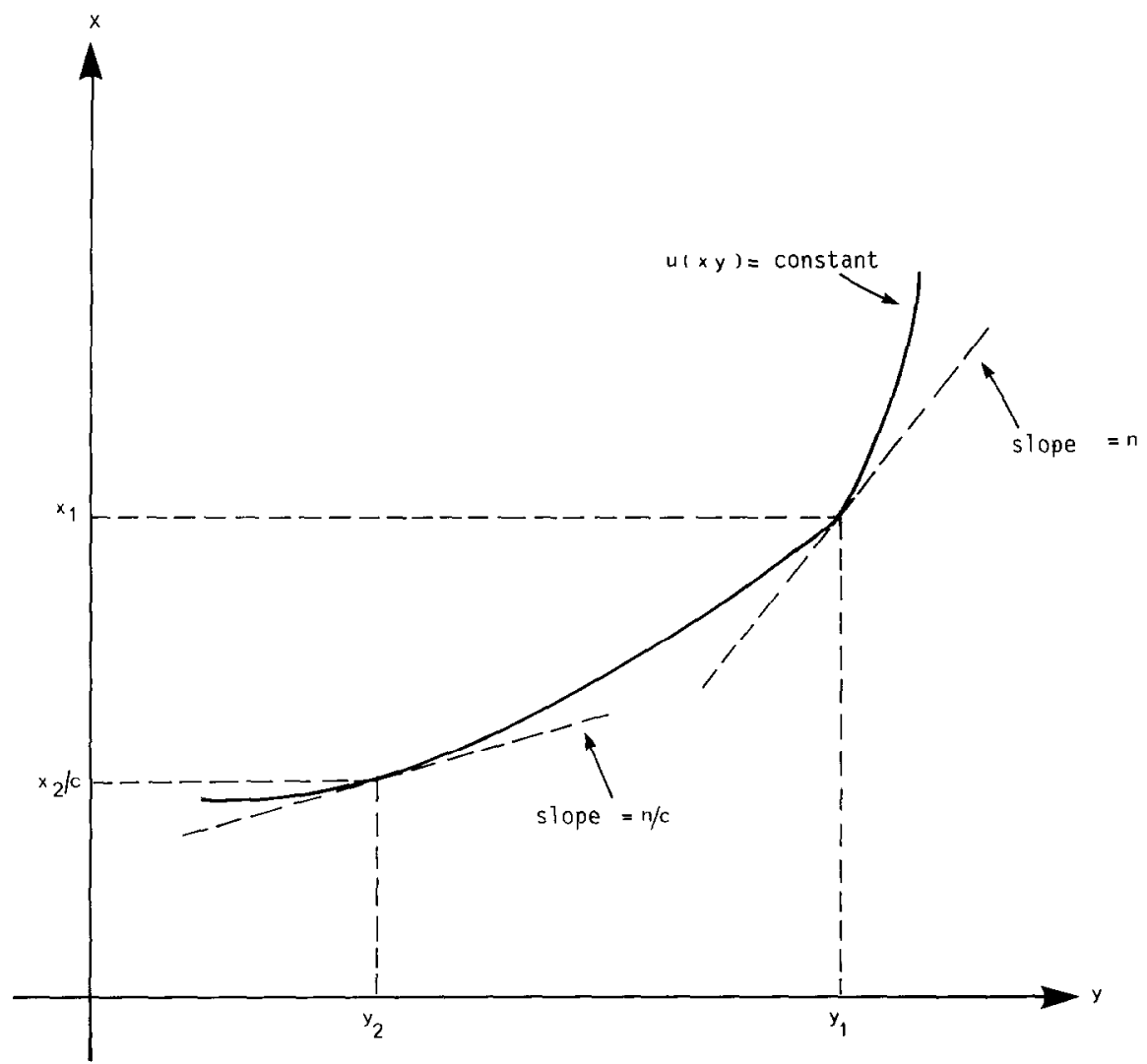

Fig. 1 


\section{Horizontal equity with income taxation}

The preceding section showed that when lump-sum taxes are available, then equating the labor supplies and the per-standard-adult consumptions of households with the same earning abilities but different sizes is not an optimal way of achieving horizontal equity. However, we show in this section that such an equality becomes the only possible way of maintaining horizontal equity when lump-sum taxes and transfers are replaced by income taxes.

In this section we assume that there is a continuum of households of each size. We denote by $F_{i}(n)$ the number of $i$-member households who earn a wage rate which is less than or equal to $n$. It is assumed that the range of wages is the interval $[0, \infty){ }^{3}$ We define $f_{i}(n)=F_{i}^{\prime}(n), i=1,2$. Let $x_{i}(n)$ and $y_{i}(n)$ be the consumption and labor supply, respectively, of an $i$-member household whose wage is $n$. Then the utilitarian social welfare function becomes

$$
\begin{aligned}
W= & \int_{0}^{\infty} u\left[x_{1}(n), y_{1}(n)\right] f_{1}(n) \mathrm{d} n \\
& +\int_{0}^{\infty} u\left[x_{2}(n) / c, y_{2}(n)\right] f_{2}(n) \mathrm{d} n .
\end{aligned}
$$

We should emphasize here that the results of this section do not depend on a specification of a social welfare function. They hold whenever we impose the principle of horizontal equity in a model of income taxation. The horizontal equity condition becomes

$$
u\left[x_{1}(n), y_{1}(n)\right]=u\left[x_{2}(x) / c, y_{2}(n)\right] \text { for all } n,
$$

and the resource constraint becomes

$$
\begin{aligned}
\int x_{1}(n) f_{1}(n) \mathrm{d} n & +\int x_{2}(n) f_{2}(n) \mathrm{d} n+R \leqq \int n y_{1}(n) f_{1}(n) \mathrm{d} n \\
& +\int n y_{2}(n) f_{2}(n) \mathrm{d} n .
\end{aligned}
$$

(All integrals are understood to be taken over the interval $[0, \infty)$, unless otherwise stated.)

\footnotetext{
${ }^{3}$ This assumption is much stronger than we actually need. For instance, it will suffice to assume that the range of wages is an interval of the form $[0, \bar{n})$, where $\bar{n}<\infty$. And even this is stronger than we need. Roughly speaking, all we need is that this interval will not be very small. To see this, recall that in the extreme case where this interval shrinks to just one point (section 2), then horizontal equity does not necessarily mean equal per-standard-adult consumptions and labor supplies.
} 
We assume that both consumption and leisure are normal goods and that $u(x, y)$ is strictly increasing in $x$ and strictly decreasing in $y$.

The objective is to maximize $\left(2^{\prime}\right)$ subject to $\left(3^{\prime}\right),\left(4^{\prime}\right)$ and the constraint that only income taxation can be used. The latter constraint restricts our choice of allocations $\left[x_{1}(\cdot), y_{1}(\cdot)\right]$ for one-member households and $\left[x_{2}(\cdot), y_{2}(\cdot)\right]$ for two-member households.

Specifically, these allocations have to be sustainable by income tax functions. Let $A_{i}$ be the set of such allocations for $i$-member households, namely:

$$
\begin{gathered}
A_{1}=\{[x(\cdot), y(\cdot)] / \text { There exists an income tax function } \\
T \text { such that for each } n,[x(n), y(n)] \text { maximizes } \\
\\
u(x, y), \text { subject to } x \leqq n y-T(n y)\}
\end{gathered}
$$

and

$$
\begin{gathered}
A_{2}=\{[x(\cdot), y(\cdot)] / \text { There exists an income tax function } \\
T \text { such that for each } n,[x(n), y(n)] \text { maximizes } \\
\\
u(x / c, y), \text { subject to } x \leqq n y-T(n y)\} .
\end{gathered}
$$

Note that these sets are determined exclusively by the underlying utilities (namely, $u$ for $A_{1}$ and $U$ for $A_{2}$ ) and not the distribution functions $F_{1}$ and $F_{2}$. Note also that we are allowing the government to employ two different tax schedules for the two types of families. Then the restriction to employ only income taxation is complied with by adding the constraint

$$
\left[x_{i}(\cdot), y_{i}(\cdot)\right] \in A_{i}, \quad i=1,2 \text {. }
$$

The main result of this section is that when horizontal equity [condition $\left(3^{\prime}\right)$ ] must be attained by income taxation [condition (8)], then one has to equate the per-standard-adult consumptions and the labor supplies of households with the same wages:

$$
x_{1}(n)=x_{2}(n) / c \quad \text { and } \quad y_{1}(n)=y_{2}(n)
$$

for all except, at most, countably many n's. (The proof of this result is relegated to appendix $B$.)

Furthermore, it is also shown in appendix $B$ that if the tax functions $T_{1}(\cdot)$ and $T_{2}(\cdot)$ support the allocations $\left[x_{1}(\cdot), y_{1}(\cdot)\right]$ and $\left[x_{2}(\cdot), y_{2}(\cdot)\right]$, respectively, then these two taxes are related to each other by

$$
T_{1}(z)=T_{2}(z) / c+z(c-1) / c,
$$


where $z(=n y)$ is gross income. Hence,

$$
T_{1}^{\prime}(z)=T_{2}^{\prime}(z) / c+(c-1) / c .
$$

Thus,

$$
T_{2}^{\prime}(z)=c T_{1}^{\prime}(z)-c+1
$$

and threfore

$$
1-T_{2}^{\prime}(z)=c\left[1-T_{1}^{\prime}(z)\right] .
$$

Since $c>1$, it follows from (13) that

$$
T_{1}^{\prime}(z)>T_{2}^{\prime}(z)
$$

The group of one-member families faces higher marginal tax rates than the group of two-member families.

\section{Optimal tax rates}

The optimal tax problem under consideration is that of maximizing the social welfare function $\left(2^{\prime}\right)$, subject to the horizontal equity principle $\left(3^{\prime}\right)$, the resource constraint $\left(4^{\prime}\right)$ and the income taxation constraint (8). However, in view of the results. of the preceding section, this problem reduces to the following:

$$
\max _{\left\{x_{1}(\cdot), y_{1}(\cdot)\right\}} \int u\left[x_{1}(n), y_{1}(n)\right] f(n) \mathrm{d} n
$$

subject to

$$
\int\left[n y_{1}(n)-p(n) x_{1}(n)\right] f(n) \mathrm{d} n \geqq R
$$

and

$$
\left(x_{1}(\cdot), y_{1}(\cdot)\right) \in A_{1},
$$

where

$$
p(n)=\left[f_{1}(n)+c f_{2}(n)\right] / f(n)
$$

and

$$
f(n)=f_{1}(n)+f_{2}(n)
$$

(Note that when the distribution of wages within each family size group is the same, i.e. when $f_{1}=\alpha f_{2}$ for some constant $\alpha>0$, then $p$ becomes a constant, independent of $n$.) 
The above problem is a standard optimal tax problem analyzed in the public finance literature [see, for instance, Mirrlees (1976)], except for one minor difference: $p$ in our problem depends on $n$. However, whether $p$ is a constant or varies with $n$ plays no role in establishing the qualitative properties of the optimal marginal tax rates [again, see Mirrlees $(1971,1976)]$.

Thus, we can still claim that optimality requires that for each $n$ the marginal rate of substitution of leisure for consumption, namely $-u_{y} / u_{x}$, should be smaller than or equal to the social marginal rate of transformation of leisure into consumption, which is, by (16), equal to $n / p$. (This result is known as the non-negativity of the optimal marginal tax rate.) Let $T_{1}$ be the income tax function which supports the optimal allocation $\left[x_{1}(\cdot), y_{1}(\cdot)\right]$. Since each household equates his marginal rate of substitution of leisure for consumption to his net wage rate which is $n\left(1-T_{1}^{\prime}\right)$, it follows that

$$
n\left(1-T_{1}^{\prime}\right) \leqq n / p
$$

or

$$
T_{1}^{\prime}\left[n y_{1}(n)\right] \geqq \frac{p(n)-1}{p(n)}=\frac{f_{2}(n)(c-1)}{f_{1}(n)+c f_{2}(n)}
$$

We can then conclude from (12) that

$$
T_{2}^{\prime}\left[n y_{2}(n)\right] \geqq-\frac{f_{1}(n)(c-1)}{f_{1}(n)+c f_{2}(n)} .
$$

Multiply (20) by $f_{1}$ and (21) by $f_{2}$ and then add them together to get:

$$
f_{1}(n) T_{1}^{\prime}\left[n y_{1}(n)\right]+f_{2}(n) T_{2}^{\prime}\left[n y_{2}(n)\right] \geqq 0 .
$$

This last result states that the weighted average of the two marginal tax rates, $T_{1}^{\prime}$ and $T_{2}^{\prime}$, should be non-negative, where the weights are $f_{1}$ and $f_{2}$, respectively. Since, by (14), we already know that $T_{1}^{\prime}>\mathrm{T}_{2}^{\prime}$, it follows that $T_{1}^{\prime}>0$, as (20) indeed confirms. Thus, the marginal tax rate imposed on onemember families should be strictly positive. However, two-member households may well face negative marginal tax rates.

Similarly, a number of authors showed that the marginal tax rate in the standard optimal tax model should be zero at the bottom and top ends of the income distribution. ${ }^{4}$ This result too holds here only with respect to the weighted average of the two taxes, $T_{1}^{\prime}$ and $T_{2}^{\prime}$. To see this, let the interval of wages be $\left[N_{1}, N_{2}\right]$. Then (20), (21) and (22) hold as equalities for $n=N_{1}$ and

\footnotetext{
${ }^{4}$ The result for the bottom end holds only if the poorest person works.
} 
$n=N_{2}$ :

$$
\begin{aligned}
& f_{1} T_{1}^{\prime}+f_{2} T_{2}^{\prime}=0, \\
& T_{1}^{\prime}=f_{2}(c-1) /\left(f_{1}+c f_{2}\right)>0
\end{aligned}
$$

and

$$
T_{2}^{\prime}--f_{1}(c-1) /\left(f_{1}+c f_{2}\right)<0 \text {. }
$$

Thus, at the end points $N_{1}$ and $N_{2}$, the marginal tax rate imposed on onemember families is positive, the marginal tax rate imposed on two-member families is negative and their weighted average is zero. ${ }^{5}$

\section{The deadweight loss of horizontal equity with income taxation}

We have seen that when horizontal equity must be achieved via income taxation, then we must have equal per-standard-adult consumptions and equal labor supplies for households with equal wages. On the other hand, such equality is nonoptimal when lump-sum taxes can be used. This suggests that when horizontal equity is to be maintained, then income taxation has some extra deadweight loss over and above the usual deadweight loss which stems from the divergence between consumer and producer prices. In this section we attempt to illustrate the magnitude of this additional loss which we will call the horizontal equity deadweight loss of income taxation.

We do this by comparing the cost of achieving horizontal equity via lumpsum taxes with the cost of achieving it via income taxation. Recall that the horizontal equity principle was imposed on, rather than implied by, the utilitarian social welfare objective. This suggests that horizontal equity imposes some cost on the utilitarian sum-of-utilities. By comparing this cost when lump-sum taxes are cmployed with the cost incurred when income taxation is used, we can get some idea about the magnitude of what we termed the horizontal equity deadweight loss of income taxation.

Specifically, we first find the optimal lump-sum taxes and transfers without imposing the principle of horizontal equity. This is done by maximizing the social welfare function $\left(2^{\prime}\right)$ subject to the resource constraint $\left(4^{\prime}\right)$. Denote the optimal level of $W$ by $\bar{W}$. We next ask: What is the minimum amount of revenue that we have to lose if we try to maintain that same level of social welfare (namely, $\bar{W}$ ) while imposing horizontal equity? This loss is the cost of

\footnotetext{
${ }^{5}$ The result that the group of one-member families faces a positive marginal tax rate everywhere, including at $N_{2}$, implies that society's insistence on horizontal equity prevents it from making Pareto-improvement changes. By setting the marginal tax rate facing this group at zero beyond the income level of $z_{2}\left(N_{2}\right)$, members of this group (namely, those with wages sufficiently close to $N_{2}$ ) will be made better off and no one will be made worse off [see Sadka (1976a)]. Of course, the principle of horizontal equity will be then violated.
} 
maintaining horizontal equity via lump-sum taxes. In a similar fashion we find the cost of maintaining horizontal equity via income taxation. The difference between the latter and the former costs illustrates the magnitude of the horizontal equity deadweight loss of income taxation.

We consider a very simple poor-rich model: there are only two wage levels, $n_{\mathrm{P}}$ ('poor') and $n_{\mathrm{R}}$ ('rich'), where $n_{\mathrm{P}}<n_{\mathrm{R}}$. There are only two families at each wage level, one small and one large. The utility function $u$ of a onemember family is specified as a CES:

$$
u(x, y)=\left\{\left[\beta x^{\rho}+(1-\beta)(K-y)^{\rho}\right]^{1 / \rho}\right\}^{1-\varepsilon} /(1-\varepsilon),
$$

where $\sigma=1 /(1-\rho)$ is the (constant) elasticity of substitution and $K$ is the endowment of leisure. $\varepsilon$ is a measure of inequality-aversion (increasing in $\varepsilon$ ). The method that can be used to calculate optimal taxes in such discrete models is discussed at length in Balcer and Sadka (1979). Here we present only the results. The values for the parameters of the model are taken from Sadka, Garfinkel and Moreland (1982) who employ the 1976 Current Population Survey:

$R=\$ 6184$ per year;

$n_{\mathrm{P}}=\$ 3.56$ per hour; ${ }^{6}$

$n_{\mathrm{R}}=\$ 6.63$ per hour; ${ }^{7}$

$\beta=0.95$

$\rho=-1.00$ (i.e., $\sigma=0.50$ );

$K=3120$ hours per year ( 60 hours per week, 52 weeks per year);

$c=1.2 .^{8}$

Two values of $\varepsilon$ are considered: $\varepsilon=0.5$ and $\varepsilon=2.0$. Table 1 presents optimal tax rates, labor supplies, pre-tax incomes, consumptions and utilities when horizontal equity is not imposed. Table 2 presents data for these variables when we pose the following question: If we try to achieve the same welfare levels (for the society) as in table 1, while imposing the principle of horizontal equity, how much revenue does the government have to give up? ${ }^{9}$

Table 3 presents the costs of horizontal equity in absolute terms and as percentages of government revenues $(R)$. It shows that when lump-sum taxation is available, horizontal equity is achieved at a cost of $\$ 217$ or 3.51 percent of $R$ (for $\varepsilon=0.5$ ). When only income taxation is allowed does the

\footnotetext{
${ }^{6}$ This is the average wage of the second lowest quintile of the population of the nonretired heads of households.

${ }^{7}$ This is the average wage of the second highest quantile of the population of nonretired heads of households.

${ }^{8}$ This figure is taken from Gaag and Smolensky (1980).

${ }^{9}$ Recall that we have here a discrete distribution of wages. This explains why the marginal income tax rate is zero at the top end of the income distribution, in contrast to the results of the preceding section which are valid only in the continuous case.
} 


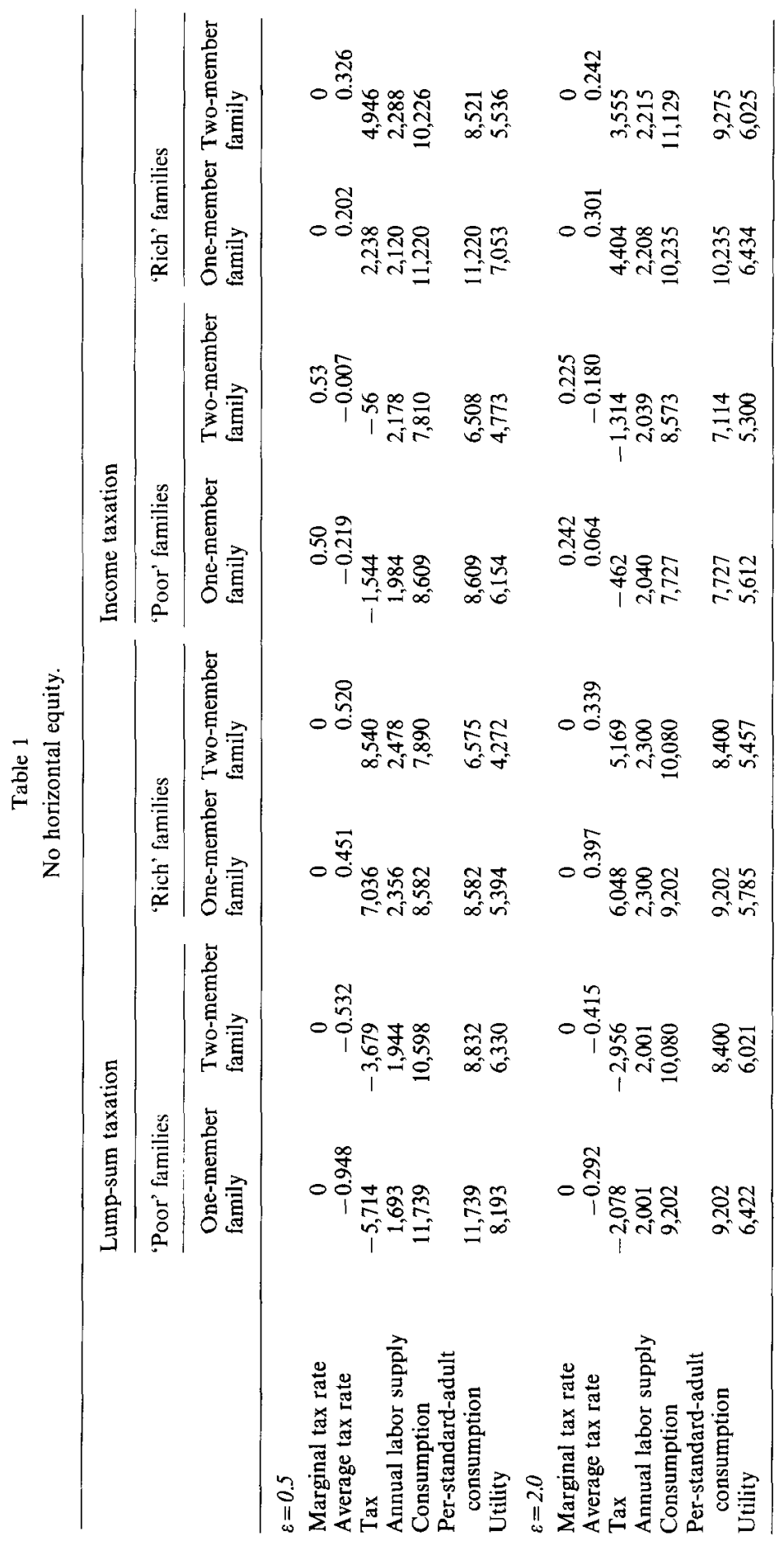




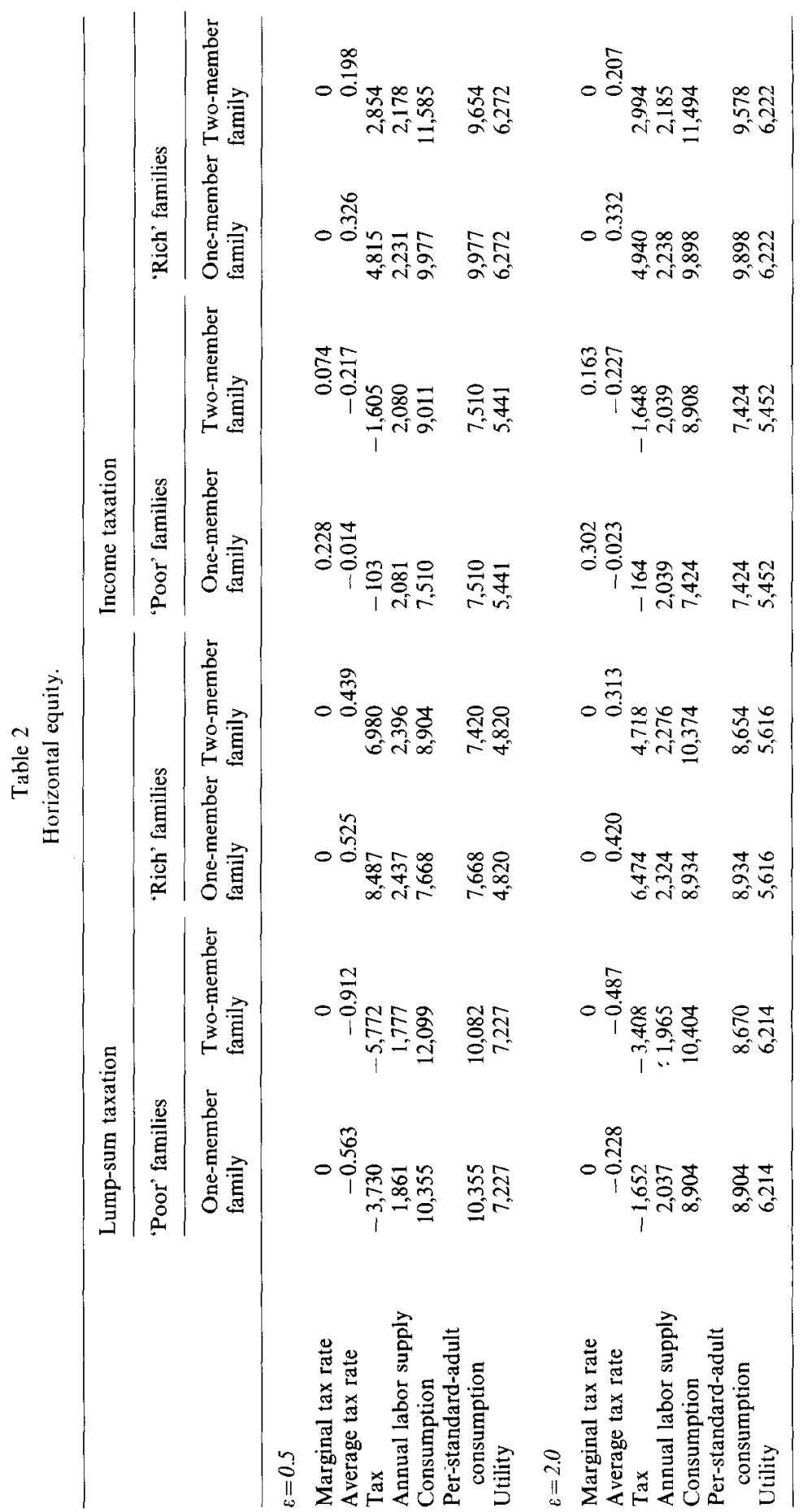


Table 3

The cost of horizontal equity.

\begin{tabular}{|c|c|c|c|c|}
\hline & \multicolumn{2}{|c|}{ L.ump-sum taxation } & \multicolumn{2}{|c|}{ Income taxation } \\
\hline & Dollars & Percentage of $R$ & Dollars & Percentage of $R$ \\
\hline $\begin{array}{l}\varepsilon=0.5 \\
\varepsilon=2.0\end{array}$ & $\begin{array}{r}217 \\
49\end{array}$ & $\begin{array}{l}3.51 \\
0.79\end{array}$ & $\begin{array}{r}221 \\
59\end{array}$ & $\begin{array}{l}3.57 \\
0.95\end{array}$ \\
\hline
\end{tabular}

cost rise to $\$ 221$ or 3.57 percent of $R$. This suggests that the horizontal equity deadweight loss of income taxation is not significant: only $\$ 4$ or 0.06 percent of $R$. When $\varepsilon=2.0$, the deadweight loss is still insignificant: $\$ 10$ or 0.16 percent of $R$.

\section{Appendix A}

Throughout this paper the principle of horizontal equity was imposed on the utilitarian sum-of-utilities social welfare function, for utilitarianism by itself does not guarantee such equity. In this appendix we discuss the question of whether a weighted sum of utilities, where higher weights are assigned to larger families, can enhance horizontal equity.

For this purpose it suffices to consider only two households: a onemember household and a two-member household, both having the same earning ability which is denoted by $n$. We ask whether there exists a constant $\lambda>0$ such that the social welfare function,

$$
W=u\left(x_{1}, y_{1}\right)+\lambda u\left(x_{2} / c, y_{2}\right)
$$

shows a preference towards horizontal equity in the sense that the optimal way to divide the national pie must preserve horizontal equity. Formally, we ask whether there exists a $\lambda>0$ such that if $\left(x_{1}, y_{1}\right)$ and $\left(x_{2}, y_{2}\right)$ maximize (A.1) subject to the resource constraint

$$
p\left(x_{1}+x_{2}\right)+R \leqq n\left(y_{1}+y_{2}\right),
$$

then they must satisfy the horizontal equity principle

$$
u\left(x_{1}, y_{1}\right)=u\left(x_{2} / c, y_{2}\right)
$$

For reasons which will be clear below we denote here the producer price of consumption by $p$ rather than normalize it to a unity, as we did in the main text.

Here it will be easier to work with the indirect utility function and with 
leisure $(l=K-y)$ rather than labor $(y)$. Let $V(p, n, I)$ and $\bar{V}(p, n, I)$, where $I$ denotes full-income, be the indirect utility function of a one-member household and a two-member household respectively, i.e.

$$
V(p, n, I)=\max u(x, K-l) \quad \text { s.t. } p x+n l \leqq I
$$

and

$$
\bar{V}(p, n, I)=\max u(x / c, K-l) \quad \text { s.t. }(c p)(x / c)+n l \leqq I .
$$

Then it is clear from (A.4) and (A.5) that

$$
\bar{V}(p, n, I)=V(c p, n I)
$$

With the aid of the indirect utility functions, the optimization problem of maximizing (A.1) subject to (A.2) reduces to the unconstrained maximization problem

$$
\max _{T}[V(p, n, I-T)+\lambda V(c p, n, I+T-R)]
$$

where $T$ is a lump-sum tax imposed on the small family, and $-(T-R)$ is the lump-sum tax imposed on the large family. The horizontal equity principle becomes now

$$
V(p, n, I-T)=V(c p, n, I+T-R)
$$

The first-order condition for (A.7) which is both necessary and sufficient Lnote that since $u$ is strictly concave in $(x, l)$, then $V$ is strictly concave in $l$ 」 is

$$
V_{I}(p, n, I-T)-\lambda V_{I}(c p, n, I+T-R) .
$$

Thus, we ask whether there exists a constant $\lambda>0$ such that (A.9) implies (A.8).

We can show that such a $\lambda$ exists for a Cobb-Douglas utility function. More generally, we can state sufficient conditions for such a $\lambda$ to exist. Suppose that $u(x, K-l)$ is homothetic in $(x, l)$. In this case $V$ takes the form

$$
V(p, n, I)=G[h(p, n) I]
$$

Since $V$ is homogeneous of degree zero in $(p, n, I)$, it follows that $h$ has to be homogeneous of degree -1 in $(p, n) . G$ is strictly increasing and strictly concave. Suppose, furthermore, that $h$ is of the form

$$
h(p, n)=h_{1}(p) h_{2}(n)
$$


Under these conditions, the required $\lambda$ exists. Define

$$
\lambda=h_{1}(1) / h_{1}(c)
$$

Then in this case (A.9) reduces to

$$
G^{\prime}[h(p, n)(1-T)] h(p, n)=G^{\prime}[h(c p, n)(I+T-R)] h(c p, n) h_{1}(1) / h_{1}(c) .
$$

Employing (A.11) and the homogeneity of degree -1 of $h$, we sce that

$$
\frac{h(c p, n) h_{1}(1)}{h_{1}(c)}=\frac{h(c, n / p) h_{1}(1)}{p h_{1}(c)}=\frac{h_{1}(1) h_{2}(n / p)}{p}=\frac{h(1, n / p)}{p}=h(p, n) .
$$

Thus, (A.13) and (A.14) imply that

$$
G^{\prime}[h(p, n)(I-T)]=G^{\prime}[h(c p, n)(I+T-R)],
$$

and hence, by the strict concavity of $G$ :

$$
h(p, n)(I-T)=h(c p, n)(I+T-R) .
$$

In view of (A.10), this last equality implies (A.8).

The reader can verify that (A.10) and (A.11) hold for a Cobb-Douglas utility function. However, these two conditions, and especially (A.11), seem very strong to us. A C.ES utility function, for instance, does not satisfy (A.11). We could not find weaker conditions than (A.10) and (A.11) and we conjecture that they are necessary as well as sufficient conditions.

\section{Appendix B}

In the appendix we prove that (3') and (8) imply (9). This is done in four steps.

(a) We first show that $[x(\cdot), y(\cdot)] \in A_{2}$ if and only if $[\bar{x}(\cdot), y(\cdot)] \in A_{1}$, where $\bar{x}(n) \stackrel{\text { def }}{=} x(n) / c$. Suppose $(x(\cdot), y(\cdot)) \in A_{2}$. Then there exists an income tax function $T$ such that for each $n, u[x(n) / c, y(n)] \geqq u(x / c, y)$ whenever $x \leqq n y-T(n y)$. Hence, $u\lceil\bar{x}(n), y(n)] \geqq u(x / c, y)$ whenever $x / c \leqq\lceil n y-T(n y)] / c$. Put $\bar{x}=x / c$ and define another $\operatorname{tax}$ function $\bar{T}$ by

$$
z-\bar{T}(z)=[z-T(z)] / c .
$$

[Note that (B.1) implies that

$$
\bar{T}(z)=T(z) / c+z(c-1) / c \cdot]
$$


Then, $u[\bar{x}(n), y(n)] \geqq u(\bar{x}, y)$, whenever $\bar{x} \leqq n y-\bar{T}(n y)$. Thus, $\bar{T}$ sustains the allocation $[\bar{x}(\cdot), y(\cdot)]$ and hence $[\bar{x}(\cdot), y(\cdot)] \in A_{1}$. The converse statement is proved in a similar way.

(b) We will state here some properties of allocations which can be supported by income tax functions. Let $v$ denote the household utility function and suppose that $[x(\cdot), y(\cdot)]$ is sustainable by some income tax function, say $T$. Then:

(i) the pre-tax income function $z(n) \stackrel{\text { def }}{=} n y(n)$ is nondecreasing in $n$ [see Mirrlees (1971)]. Thus, if $\left[x_{i}(\cdot), y_{i}(\cdot)\right] \in A_{i}$, then $z_{i}(n)$ is nondecreasing in $n$;

(ii) for all except, at most, countably many $n$ 's, there is a unique solution to the household utility-maximization problem: $\max v(x, y)$, subject to $x \leqq n y-$ $T(n y)$ [see Sadka (1976a)];

(iii) with no loss of generality we may assume that if $z \geqq 0$, then there exists $n \in[0, \infty)$ such that $z(n)=z$ [see Sadka (1976a)].

(c) Next we show that if (i) $[x(\cdot), y(\cdot)]$ and $[\vec{x}(\cdot), \vec{y}(\cdot)]$ are two allocations which can be supported by income tax functions, say $T$ and $\bar{T}$, respectively, and (ii) $v[x(n), y(n)]=v[\bar{x}(n), \bar{y}(n)]$ for all $n$, then $T=\bar{T}$ and $[x(n), y(n)]=$ $[\bar{x}(n), \bar{y}(n)]$ for all except, at most, countably many $n$ 's. Suppose to the contrary that $T \neq \bar{T}$, i.e. there exists $z_{0} \geqq 0$ such that $T\left(z_{0}\right)>\bar{T}\left(z_{0}\right)$. By (b)(iii) above, there exists $n_{0} \in[0, \infty)$ such that $z\left(n_{0}\right)=n_{0} y\left(n_{0}\right)=z_{0}$. Since $T\left(z_{0}\right)>\bar{T}\left(z_{0}\right)$, it follows that $v\left[\bar{x}\left(n_{0}\right), \bar{y}\left(n_{0}\right)\right]>v\left[x\left(n_{0}\right), y\left(n_{0}\right)\right]$, which is a contradiction. Hence, $T=\bar{T}$, and it follows from (b)(ii) that $x(n)=\bar{x}(n)$ and $y(n)$ $=\bar{y}(n)$ for all except, at most, countably many $n$ 's.

(d) Now we prove that (3') and (8) imply (9). Since $\left(x_{2}(\cdot), y_{2}(\cdot)\right) \in A_{2}$, then it follows from (a) above that $\left[x_{2}(\cdot) / c, y_{2}(\cdot)\right] \in A_{1}$. We also know that $\left[x_{1}(\cdot), y_{1}(\cdot)\right] \in A_{1}$ and that $u\left[x_{2}(n) / c, y_{2}(n)\right]=u\left[x_{1}(n), y_{1}(n)\right]$ for all $n$. Therefore, it follows from (c) that $x_{2}(n) / c=x_{1}(n)$ and $y_{2}(n)=y_{1}(n)$ for all except, at most, countably many n's.

Furthermore, if we denote the taxes which support the allocations $\left[x_{1}(\cdot), y_{1}(\cdot)\right]$ and $\left[x_{2}(\cdot), y_{2}(\cdot)\right]$ by $T_{1}$ and $T_{2}$, respectively, then (a) [especially eq. (B.1)] and (c) can determine the relationship between $T_{1}$ and $T_{2}$. Since $\left[x_{2}(\cdot), y_{2}(\cdot)\right] \in A_{2}$, then $\left[\bar{x}_{2}(\cdot), y_{2}(\cdot)\right] \in A_{1}$, where $\bar{x}_{2}(n)=x_{2}(n) / c$. Eq. (B.1) shows that the tax function $\bar{T}_{2}$ defined by

$$
\bar{T}_{2}(z)=T_{2}(z) / c+z(c-1) / c
$$

supports $\left[\bar{x}_{2}(\cdot), y_{2}(\cdot)\right]$. By $(\mathrm{c}), \bar{T}_{2}=T_{1}$. This proves $(10)$.

\section{References}

Atkinson, A.B., 1980, Horizontal equity and the distribution on the tax burden, in: H.J. Aaron and M.J. Boskin, eds., The economics of taxation, Brookings Institution, 1-19.

Atkinson, A.B. and J.E. Stiglitz, 1976, The design of tax structure: Director versus indirect taxation, Journal of Public Economics 6, 55-75. 
Atkinson, A.B. and J.E. Stiglitz, 1980, Lectures on public economics (McGraw-Hill).

Balcer, Y. and E. Sadka, 1979, Family size, personal income tax credits and horizontal equity, Discussion paper no. 588-79, Institute for Research on Poverty, The University of WisconsinMadison.

Balcer, Y. and E. Sadka, 1982, Horizontal equity, income taxation and self-selection with an application to income tax credits, Journal of Public Economics 19, 291-309.

Berliant, M.C. and R.P. Strauss, 1985, On recent expositions of horizontal and vertical equity, mimeo.

Feldstein, M.S., 1976, On the theory of tax reform, Journal of Public Economics 6, 77-104.

Gaag, J. Van der and E. Smolensky, 1980, Consumer expenditures and the evaluation of levels of living, Institute for Research on Poverty, University of Wisconsin-Madison, mimeo.

Mirrlees, J.A., 1971, An exploration into the theory of optimum income taxation, Review of Economic Studies 38, 175-208.

Mirrlees, J.A., 1976, Optimal tax theory: A synthesis, Journal of Public Economics 6, 327-358.

Nerlove, M., A. Razin and E. Sadka, 1984, Income redistribution policies with endogenous fertility, Journal of Public Economics 24, 221-230.

Nerlove, M., A. Razin and E. Sadka, forthcoming, Household and economy: Parental and filial equity (Academic Press).

Pollak, R.A. and T.J. Wales, 1978, Estimation of complete demand systems from household budget data: The linear and quadratic expenditure systems, American Economic Review 68, $348-359$.

Pollak, R.A. and T.J. Wales, 1979, Welfare comparisons and equivalent scales, American Economic Review, Papers and Proceedings 69, 216-221.

Pollak, R.A. and T.J. Wales, 1980, Comparison of the quadratic expenditure system and translog demand systems with alternative specifications of demographic effects, Econometrica 48, 575612.

Pollak, R.A. and T.J. Wales, 1981, Demographic variables in demand analysis, Econometrica 49, 1533-1551.

Sadka, E., 1976a, On income distribution, incentive effects and optimal income taxation, Review of Economic Studies 43, 261-268.

Sadka, E., 1976b, Social welfare and income distribution, Econometrica 44, $1239-1251$.

Sadka, E., I. Garfinkel and K. Moreland, 1982, Income testing and social welfare, in: I. Garfinkel, ed., Income-tested transfer programs (Academic Press), 291-313.

Stiglitz, J.E., 1982, Utilitarianism and horizontal equity: The case for random taxation, Journal of Public Economics 18, 133. 